\title{
TINGKAT KEPUASAN PENUMPANG TERHADAP KUALITAS PELAYANAN JASA KERETA API LOKAL PENATARAN RELASI SIDOARJO - MALANG KOTA LAMA
}

\author{
Ahmad Bagus Ismail ${ }^{1}$, email: ahmadbagus.ismail@ptdisttd.ac.id \\ Tonny Agus Setiono ${ }^{2}$, email: tonnyagus.setiono@ptdisttd.ac.id \\ I Made Suraharta ${ }^{3}$, email: isuraharta@ptdisttd.ac.id \\ 1,2,3 Manajemen Transportasi Perkeretaapian, Politeknik Transportasi Darat Indonesia - STTD
}

\begin{abstract}
ABSTRAK
Keberagaman karakteristik dari penumpang memungkinkan adanya perbedaan penilaian kepuasan, padahal pada dasarnya pihak penyelenggara perkeretaapian harus mampu menciptakan kepuasan secara menyeluruh bagi pelanggan. Melihat kondisi eksisting pada KA Lokal Penataran, pelayanan yang diberikan kepada pengguna jasa di atas kereta masih kurang baik mengingat okupansinya yang rata-rata relatif tinggi. Oleh karena itu, perlu diketahui tingkat kepuasan penumpang terhadap kualitas pelayanan jasa Kereta Api Lokal Penataran relasi Sidoarjo - Malang Kota Lama. Penelitian ini dilakukan untuk mengetahui tingkat kepuasan penumpang dengan metode analisis deskriptif karakteristik penumpang. Indeks kepuasan pelanggan dihitung menggunakan metode analisis CSI (Customer Satisfaction Index). Penilaian tingkat pelayanan yang diberikan PT. KAI khususnya DAOP 8 Surabaya dilihat dari segi tingkat kinerja dan kepentingan. Hasilnya dapat diketahui bahwa tingkat kinerja pelayanan dapat diartikan Cukup Puas, sedangkan tingkat kepentingan dapat diartikan Penting.
\end{abstract}

Kata Kunci: Tingkat kepuasan, penumpang, kualitas pelayanan jasa, kereta api lokal

\section{ABSTRACT}

The diversity of characteristics of passengers allows for different satisfaction ratings, whereas basically the railway operator must be able to create overall satisfaction for customers. Seeing the existing conditions on the Penataran Local Railway, the services provided to service users on the train are still not good considering the relatively high average occupancy. Therefore, it is necessary to know the level of passenger satisfaction with the service quality of the local train service upgrading the Sidoarjo Malang Kota Lama relationship. This research was conducted to determine the level of passenger satisfaction with the descriptive analysis method of passenger characteristics. The customer satisfaction index is calculated using the CSI (Customer Satisfaction Index) analysis method. Assessment of the level of service provided by PT. KAI especially DAOP 8 Surabaya in terms of performance level and importance. The result can be seen that the level of service performance can be interpreted as quite satisfied, while the level of importance can be interpreted as important.

Keywords: Satisfaction level, passengers, service quality, local trains.

\section{PENDAHULUAN}

Kereta api merupakan salah satu angkutan penumpang yang menawarkan banyak keunggulan dan memberi banyak manfaat. Berbagai keunggulan yang ditawarkan kereta api antara lain cepat, nyaman, bebas dari kemacetan lalu lintas jalan raya, kapasitas angkut yang besar, serta perjalanannya terjadwal. Selain itu angkutan kereta api juga lebih ramah lingkungan dibandingkan moda angkutan umum lainnya yang lebih banyak menghasilkan polusi udara sehingga mencemari lingkungan.
Salah satu kereta api penumpang di wilayah Daerah Operasi (DAOP) 8 Surabaya untuk lintas Sidoarjo Malang Kota Lama adalah kereta api lokal Penataran. KA Lokal Penataran mengangkut penumpang dari Surabaya Kota ke Blitar dan sebaliknya dari Blitar ke Surabaya Kota yang berjarak 169,6 km. Dalam sehari angkutan ini beroperasi 8 kali perjalanan pergi pulang menggunakan 4 rangkaian KA. Tarif yang ditetapkan pada KA Lokal Penataran adalah 15.000 rupiah dengan waktu tempuh perjalanan kurang lebih 6 jam dan berhenti di 25 stasiun antara. Angkutan KA Lokal Penataran dirasa melebihi dari nilai okupansi 
maksimal yang telah ditetapkan jika dilihat dari ratarata tingkat okupansinya yang relatif tinggi yaitu berada pada kisaran diatas $100 \%$ dari total kapasitas tempat duduk sebesar 636 dengan stamformasi 6K3$1 \mathrm{KMP} 3$.

Kondisi di atas menunjukkan pelayanan penumpang akan kinerja pelayanan yang diberikan kepada pelanggan KA Lokal Penataran dirasa masih belum optimal dalam memenuhi kepuasan pelanggan yang memiliki berbagai macam karakteristik dan kepentingan tersebut. Keberagaman ini tentunya juga menyebabkan perbedaan penilaian akan kualitas kinerja pelayanan yang diberikan. Penyelenggara perkeretaapian harus mampu menciptakan kepuasan secara menyeluruh bagi pelanggan dengan beragam karakteristik tersebut.

Pada beberapa penelitian sebelumnya telah dibahas terkait Evaluasi Kualitas Pelayanan KA Ekonomi Kahuripan Relasi Kediri-Padalarang”. Penelitian ini bertujuan untuk meramalkan jumlah penumpang 5 tahun yang akan datang dan menghitung kebutuhan sarana yang diperlukan untuk meningkatkan kualitas pelayanan pada KA Ekonomi Kahuripan Rika (2009). Evaluasi Kinerja Angkutan KRDI Sri Lelawangsa Lintas Medan-Binjai". Penelitian ini bertujuan untuk mengetahui kondisi eksisting KRDI Sri Lelawangsa yang meliputi okupansi penumpang, waktu tempuh, dan kelambatan. Kemudian, disini peneliti juga membandingkan pelayanan di dalam KRDI dan di stasiun dengan standar pelayanan yang terdapat pada Peraturan Menteri Ali (2011).

Maka dari itu, pada penelitian ini penulis mencoba menganalisa tingkat kepuasan konsumen khususnya penumpang KA Lokal Penataran relasi Sidoarjo Malang Kota Lama, yang merupakan tempat penulis melaksanakan praktek kerja lapangan menggunakan beberapa atribut kualitas pelayanan di dalam kereta yang berpengaruh terhadap kepuasan pelanggan.

Penelitian ini difokuskan untuk menentukan tingkat kepuasan penumpang terhadap kualitas pelayanan penumpang di atas KA Lokal Penatarans. Untuk ruang lingkup pelayanannya hanya tertuju pada pelayanan yang terdapat di dalam kereta yang akan diukur kinerjanya, antara lain: fasilitas dan kondisi di dalam KA Lokal Penataran, pelayanan oleh petugas di dalam kereta, ketepatan jadwal perjalanan yang sesuai dengan standar pelayanan minimum.

\section{METODE PENELITIAN}

Dalam rangka mengkaji kepuasan penumpang khususnya KA Lokal Penataran, makan diperlukan pengumpulan data baik data yang bersifat kualitatif dan kuantitatif. Data tersebut dapat berupa data primer maupun data sekunder yag akan digunakan sebagai petunjuk dan pedoman untuk pengkajian yang dilakukan.

Dalam metode penelitian ini terdapat beberapa proses pengumpulan data untuk menunjang penelitian, yaitu :

1. Sumber Data

a. Data Primer

Data primer merupakan data yang diperoleh dengan cara melakukan survei maupun pengamatan secara langsung di lapangan mengenai kondisi eksisting yang ada. Data primer ini merupakan kunci utama bagi penulis dalam melakukan penelitian. Data yang diambil dari penelitian ini adalah dengan melakukan survei dan pengamatan langsung di lapangan terkait pelayanan di dalam KA Lokal Penataran.

b. Data Sekunder

Data sekunder merupakan data yang diperoleh secara tidak langsung atau melalui perantara (diperoleh dari pihak lain). Data sekunder ini biasanya berupa catatan atau arsip yang dipublikasikan atau tidak dipublikasikan. Data ini merupakan data yang dibutuhkan untuk mendukung atau menjadi pelengkap bagi data primer dalam melakukan analisis terhadap permasalahan. Adapun data sekunder yang diperoleh menggunakan metode sebagai berikut :

1) Metode Kepustakaan

Metode ini dilakukan dengan menggunakan bukubuku ataupun literatur yang berhubungan dan mendukung dalam penelitian Kertas Kerja Wajib ini.

2) Metode Institusional

Metode ini dilakukan dengan mengumpulkan data dari berbagai instansi yang berhubungan dengan penelitian ini, yaitu data dari DAOP 8 Surabaya, antara lain :

a) Volume naik turun penumpang.

b) Jadwal perjalanan KA Lokal Penataran.

Selain data diatas, data sekunder lainnya yang digunakan adalah standar pelayanan yang terdapat pada PM No. 63 Tahun 2019. Adapun tempat penelitian ini dilakukan yaitu pada Daerah Operasi 8 Surabaya khususnya di lintas Sidoarjo - Malang Kota Lama.

\section{Peralatan yang Digunakan}

Beberapa peralatan yang digunakan untuk membantu jalannya penelitian ini adalah sebagai berikut :

a. Kuisioner Penelitian

Kuisioner digunakan untuk menghimpun pendapat dari masyarakan khususnya penumpang KA Lokal Penataran mengenai kualitas kinerja dan tingkat kepentingan fasilitas dan pelayanan yang diberikan PT. Kereta Api Indonesia (Persero) selaku penyelenggara angkutan penumpang KA Lokal Penataran.

b. Kamera 
Kamera digunakan untuk mengambil gambar guna keperluan data primer berupa konsisi eksisting fasilitas dan pelayanan KA Lokal Penataran.

c. Software SPSS.22

Software ini digunakan penulis untuk membantu dalam melakukan analisis data yaitu pada analisis CSI, IPA, dan uji Chi Square.

\section{HASIL DAN PEMBAHASAN}

\subsection{Analisis Deskriptif}

a. Karakteristik Penumpang

Karakteristik penumpang ini terdiri atas 9 variabel karakteristik. Adapun karakteristik penumpang KA Lokal Penataran adalah sebagai berikut :

1. Jenis Kelamin

Berikut merupakan data frekuensi jenis kelamin penumpang pada KA Lokal Penataran :

Tabel 1 Jenis Kelamin Penumpang KA Lokal Penataran

\begin{tabular}{|c|l|c|}
\hline No. & Jenis Kelamin & Frekuensi \\
\hline 1 & Laki-laki & 56 \\
\hline 2 & Perempuan & 44 \\
\hline \multicolumn{2}{|c|}{ Total } & 100 \\
\hline
\end{tabular}

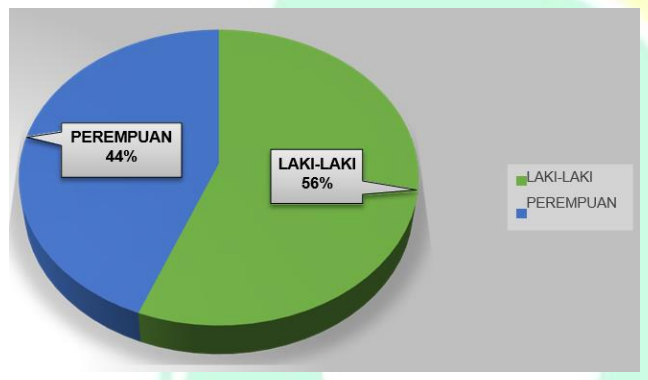

Gambar 1 Prosentase Jenis Kelamin Penumpang KA Lokal Penataran

Dari gambar diagram diatas dapat diketahui bahwa prosentase jenis kelamin penumpang KA Lokal Penataran adalah $56 \%$ untuk jenis kelamin laki-laki dan $44 \%$ untuk jenis kelamin perempuan.

2. Usia

Berikut merupakan data frekuensi usia penumpang pada KA Lokal Penataran :

Tabel 2 Usia Penumpang KA Lokal Penataran

\begin{tabular}{|c|c|c|}
\hline No. & Usia & Frekuensi \\
\hline 1 & $\leq 20$ Tahun & 23 \\
\hline 2 & $21-30$ Tahun & 31 \\
\hline 3 & $31-40$ Tahun & 25 \\
\hline 4 & $41-50$ Tahun & 14 \\
\hline 5 & $\geq 51$ Tahun & 7 \\
\hline \multicolumn{2}{|c|}{ Total } & 100 \\
\hline
\end{tabular}

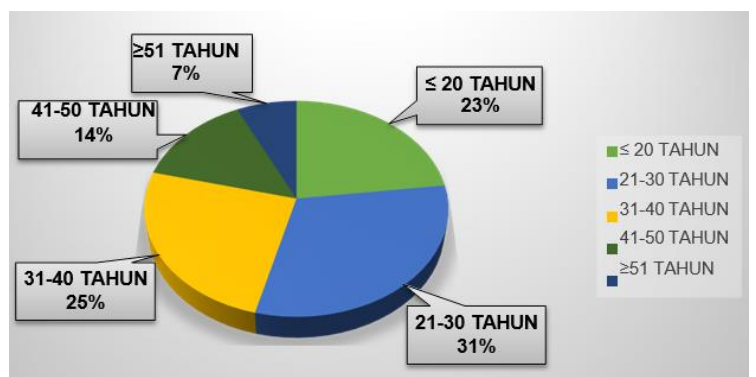

Gambar 2 Prosentase Usia Penumpang KA Lokal Penataran

Dari gambar diagram diatas dapat diketahui bahwa prosentase usia penumpang KA Lokal Penataran adalah $23 \%$ untuk usia $\leq 20$ tahun, $31 \%$ untuk usia 21 30 tahun, $25 \%$ untuk usia $31-40$ tahun, $14 \%$ untuk usia 41-50 tahun, dan 7\% untuk usia $\geq 51$ tahun. Dari data tersebut dapat disimpulkan bahwa penumpang KA Lokal Penataran didominasi oleh golongan remaja dan orang dewasa.

Tabel 3 Jenis Pekerjaan Penumpang KA Lokal Penataran

\begin{tabular}{|c|l|c|}
\hline No. & \multicolumn{1}{|c|}{ Jenis Pekerjaan } & Frekuensi \\
\hline 1 & Pelajar/Mahasiswa & 33 \\
\hline 2 & Pegawai Negeri Sipil (PNS) & 19 \\
\hline 3 & Pegawai BUMN/BUMD & 7 \\
\hline 4 & Pegawai Swasta & 13 \\
\hline 5 & TNI/Polri & 5 \\
\hline 6 & Wiraswasta & 5 \\
\hline 7 & Ibu Rumah Tangga & 10 \\
\hline 8 & Lainnya & 8 \\
\hline \multicolumn{2}{|c|}{ Total } & 100 \\
\hline
\end{tabular}

3. Jenis Pekerjaan

Berikut merupakan data frekuensi jenis pekerjaan penumpang pada KA Lokal Penataran ditunjukkan pada tabel 3 .

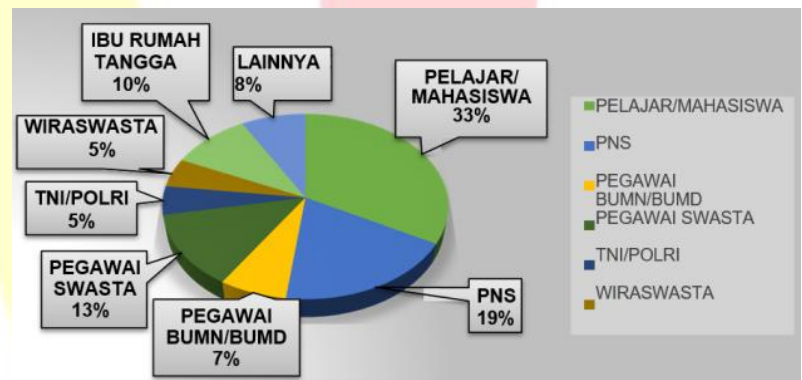

Gambar 3 Prosentase Jenis Pekerjaan Penumpang KA Lokal Penataran

4. Tingkat Pendapatan dalam Satu Bulan

Berikut merupakan data frekuensi tingkat pendapatan penumpang pada KA Lokal Penataran dalam satu bulan : 
Tabel 4 Tingkat Pendapatan Penumpang KA Lokal Penataran dalam Satu Bulan

\begin{tabular}{|c|l|c|}
\hline No. & \multicolumn{1}{|c|}{ Tingkat Pendapatan } & Frekuensi \\
\hline 1 & $<\operatorname{Rp~500.000~}$ & 33 \\
\hline 2 & $\operatorname{Rp~500.000-Rp~1.500.000~}$ & 14 \\
\hline 3 & $\operatorname{Rp~1.500.000-Rp~3.000.000~}$ & 11 \\
\hline 4 & $\operatorname{Rp~3.000.000-Rp~5.000.000~}$ & 24 \\
\hline 5 & $\operatorname{Rp~5.000.000-Rp~9.000.000~}$ & 15 \\
\hline 6 & $>\operatorname{Rp~9.000.000~}$ & 3 \\
\hline \multicolumn{2}{|c|}{ Total } \\
\hline
\end{tabular}

Gambar 4 Prosentase Tingkat Pendapatan Penumpang KA Lokal Penataran dalam Satu Bulan

Dari gambar diagram diatas dapat diketahui bahwa prosentase tingkat pendapatan penumpang KA Lokal Penataran didominasi oleh penumpang berpenghasilan $<\mathrm{Rp} 500.000$ sebesar 33\% dan Rp 3.000.000-Rp 5.000 .000 sebesar $24 \%$. Kemudian untuk prosentase berpenghasilan penumpang terendah adalah $3 \%$ untuk > Rp 9.000.000

\section{Maksud Perjalanan}

Dari tabel 5 dapat diketahui bahwa prosentase maksud perjalanan penumpang KA Lokal Penataran dari arah Sidoarjo ke Malang Kota Lama ataupun sebaliknya adalah sebesar $31 \%$ untuk rekreasi, $21 \%$ untuk bekerja, $19 \%$ untuk sekolah/kuliah dan lainnya, serta $10 \%$ untuk kepentingan keluarga. Berdasarkan uraian diatas maksud perjalanan terbanyak yaitu untuk rekreasi dan bekerja mengingat kota malang merupakan destinasi wisata terbesar di Jawa Timur dan sidoarjo merupakan kota industri dan perkantoran. Berikut merupakan data frekuensi maksud dari perjalanan penumpang pada KA Lokal Penataran :

Tabel 5 Maksud Perjalanan

\begin{tabular}{|c|l|c|}
\hline No. & Maksud Perjalanan & Frekuensi \\
\hline 1 & Sekolah/Kuliah & 19 \\
\hline 2 & Bekerja & 21 \\
\hline 3 & Rekreasi & 31 \\
\hline 4 & Kepentingan Keluarga & 10 \\
\hline 5 & Lainnya & 19 \\
\hline \multicolumn{2}{|c|}{ Total } & 100 \\
\hline
\end{tabular}

Dari tabel diatas dapat diketahui bahwa prosentase maksud perjalanan penumpang KA Lokal Penataran dari arah Sidoarjo ke Malang Kota Lama ataupun sebaliknya adalah sebesar $31 \%$ untuk rekreasi, $21 \%$ untuk bekerja, $19 \%$ untuk sekolah/kuliah dan lainnya, serta $10 \%$ untuk kepentingan keluarga. Berdasarkan uraian diatas maksud perjalanan terbanyak yaitu untuk rekreasi dan bekerja mengingat kota malang merupakan destinasi wisata terbesar di Jawa Timur dan sidoarjo merupakan kota industri dan perkantoran.

\section{Alasan Menggunakan KA Lokal Penataran}

Berikut merupakan data frekuensi alasan penumpang menggunakan moda transportasi KA Lokal Penataran :

Tabel 6 Alasan Menggunakan KA Lokal Penataran

\begin{tabular}{|c|l|c|}
\hline No. & Alasan Menggunakan KA & Frekuensi \\
\hline 1 & Murah & 31 \\
\hline 2 & Waktu Tempuh Lebih Cepat & 27 \\
\hline 3 & Terjadwal/Jadwal Pasti & 20 \\
\hline 4 & Aman dan Nyaman & 15 \\
\hline 5 & Lainnya & 7 \\
\hline \multicolumn{2}{|c|}{ Total } & 100 \\
\hline
\end{tabular}

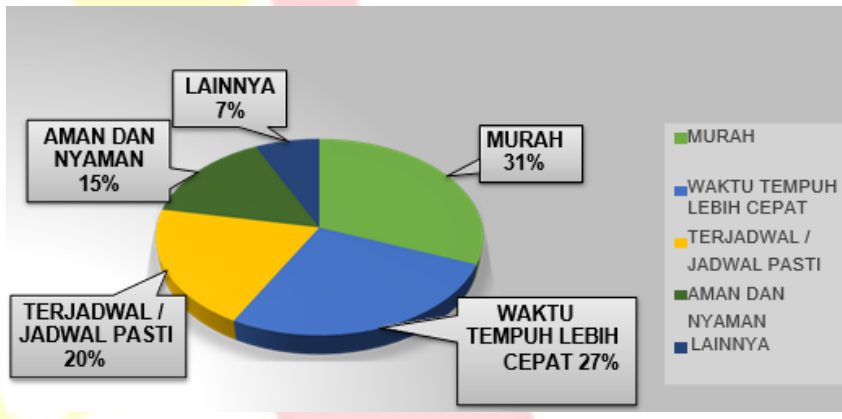

Gambar 5 Prosentase Alasan Penumpang Menggunakan KA Lokal Penataran

Dari gambar diagram diatas dapat diketahui bahwa prosentase alasan penumpang menggunakan jasa KA Lokal Penataran adalah 31\% karena murah, 27\% karena waktu tempuh lebih cepat, $20 \%$ karena jadwal yang pasti/terjadwal, $15 \%$ karena aman dan nyaman, dan $7 \%$ memilih lainnya. Dari uraian tersebut, dapat disimpulkan bahwa alasan penumpang memilih jasa KA Lokal Penataran dikarenakan harga tiket yang murah, waktu tempuh yang lebih cepat dibanding moda transportasi lainnya, dan jadwal yang pasti/terjadwal.

\section{Frekuensi Menggunakan KA Lokal Penataran}

Berikut merupakan data frekuensi penumpang dalam menggunakan jasa KA Lokal Penataran : 
Tabel 7 Frekuensi Menggunakan KA Lokal Penataran

\begin{tabular}{|c|l|c|}
\hline No. & $\begin{array}{l}\text { Frekuensi } \\
\text { Menggunakan KA }\end{array}$ & Frekuensi \\
\hline 1 & $1-2$ kali & 50 \\
\hline 2 & $3-5$ kali & 33 \\
\hline 3 & $5-7$ kali & 10 \\
\hline 4 & $7-10$ kali & 5 \\
\hline 5 & $>10$ kali & 2 \\
\hline \multicolumn{2}{|c|}{ Total } & 100 \\
\hline
\end{tabular}

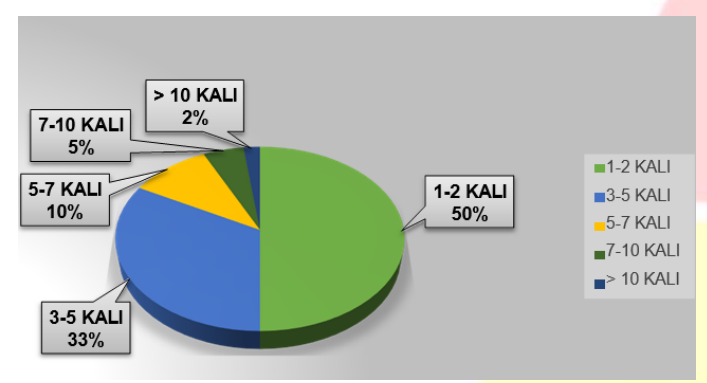

Gambar 6 Frekuensi Penumpang Menggunakan KA Lokal Penataran

Dari gambar diagram diatas dapat diketahui bahwa prosentase frekuensi penumpang menggunakan jasa KA Lokal Penataran adalah 50\% sebanyak 1-2 kali, $33 \%$ sebanyak 3-5 kali, $10 \%$ sebanyak 5-7 kali, 5\% sebanyak 7-10 kali, dan 2\% sebanyak >10 kali. Dari uraian tersebut, frekuensi terbesar penumpang menggunakan jasa KA Lokal Penataran sebanyak 1-2 kali

8. Moda Transportasi yang Digunakan Menuju Stasiun

Berikut merupakan data frekuensi moda transportasi yang digunakan penumpang KA Lokal Penataran dalam perjalanan dari tempat awal menuju stasiun keberangkatan :

Tabel 8. Moda Transportasi yang Digunakan Menuju Stasiun

\begin{tabular}{|c|l|c|}
\hline No. & Moda Menuju Stasiun & Frekuensi \\
\hline 1 & Jalan Kaki & 31 \\
\hline 2 & Angkutan Umum & 28 \\
\hline 3 & Kendaraan Pribadi & 36 \\
\hline 4 & Taksi & 0 \\
\hline 5 & Ojek Online & 5 \\
\hline \multicolumn{2}{|c|}{ Total } & 100 \\
\hline
\end{tabular}

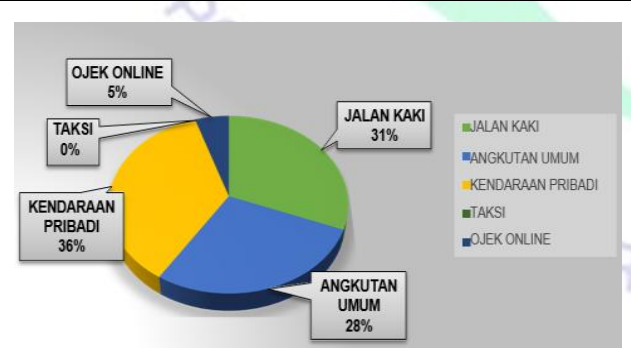

Gambar 7 Pemilihan Moda yang Digunakan
Dari gambar diagram diatas dapat diketahui bahwa prosentase moda transportasi yang digunakan penumpang dari tempat asal ke stasiun keberangkatan adalah 36\% memilih kendaraan pribadi, $31 \%$ memilih jalan kaki, 28\% memilih angkutan umum, 5\% memilih ojek online, dan 0\% memilih taksi. Dari uraian tersebut, moda yang digunakan penumpang menuju stasiun terbanyak adalah memilih untuk menggunakan kendaraan pribadi, jalan kaki, dan angkutan umum.

9. Moda Transportasi yang Digunakan Dari Stasiun Menuju Tempat Tujuan

Berikut merupakan data frekuensi moda transportasi yang digunakan penumpang KA Lokal Penataran dari stasiun tujuan menuju tempat tujuan :

Tabel 9 Moda Transportasi yang Digunakan Dari Stasiun Mejunu Tempat Tujuan

\begin{tabular}{|c|l|c|}
\hline No. & $\begin{array}{l}\text { Moda Dari Stasiun } \\
\text { Menuju Tujuan }\end{array}$ & Frekuensi \\
\hline 1 & Jalan Kaki & 14 \\
\hline 2 & Angkutan Umum & 37 \\
\hline 3 & Kendaraan Pribadi & 18 \\
\hline 4 & Taksi & 4 \\
\hline 5 & Ojek Online & 27 \\
\hline \multicolumn{2}{|c|}{ Total } & 100 \\
\hline
\end{tabular}

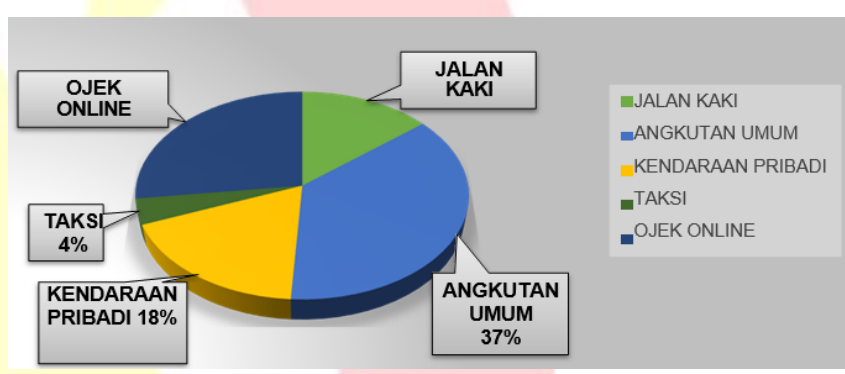

Gambar 8 Pemilihan Moda yang Digunakan Dari Stasiun Menuju Tempat Tujuan

Dari gambar 8 dapat diketahui bahwa prosentase moda transportasi yang digunakan penumpang dari stasiun tujuan ke tempat tujuan akhir adalah 37\% memilih angkutan umum, 27\% memilih ojek online, 18\% memilih kendaraan pribadi, $14 \%$ memilih jalan kaki, dan $4 \%$ memilih taksi. Dari uraian tersebut, dapat disimpulkan bahwa moda yang dipilih penumpang dari stasiun tujuan menuju tempat tujuan akhir sebagian besar memilih moda angkutan umum dan ojek online

3.2 Analisis IPA (Importance Performance Analysis)

Importance Performance Analysis dilakukan untuk membandingkan penilaian penumpang KA Lokal Penataran terhadap tingkat kepentingan dari pelayanan (importance) dengan kualitas kinerja (performance). 
Dalam analisis ini dilakukan dengan cara menghitung skor tingkat kepentingan penumpang KA Lokal Penataran dan skor tingkat kinerja pelayanan yang diberikan KA Lokal Penataran yang kemudian digambarkan ke dalam suatu diagram kartesius.

Menghitung Bobot Skor Tingkat Kinerja dan Tingkat Kepentingan Dalam menentukan bobot skor total tingkat kinerja dan tingkat kepentingan dilakukan dengan cara menjumlahkan seluruh skor penilaian yang didapat yang didasarkan pada perkalian antara skor penilaian dengan bobot item jawaban

Tabel 8 Skor Kinerja dan Kepentingan Pelayanan Kondisi Tempat Duduk

\begin{tabular}{|c|c|c|c|c|c|c|}
\hline \multicolumn{7}{|c|}{ TINGKAT KINERJA (Xi) } \\
\hline PENILAIAN & 1 & 2 & 3 & 4 & 5 & \\
\hline $\begin{array}{l}\text { JUMLAH } \\
\text { JAWABAN }\end{array}$ & 0 & 11 & 44 & 41 & 4 & \\
\hline $\begin{array}{l}\text { JUMLAH } \\
\text { SKOR }\end{array}$ & 0 & 22 & 132 & 164 & 20 & 338 \\
\hline \multicolumn{7}{|c|}{ TINGKAT KEPENTINGAN (Yi) } \\
\hline PENILAIAN & 1 & 2 & 3 & 4 & 5 & \\
\hline $\begin{array}{l}\text { JUMLAH } \\
\text { JAWABAN }\end{array}$ & 0 & 0 & 0 & 30 & 70 & \\
\hline $\begin{array}{c}\text { JUMLAH } \\
\text { SKOR }\end{array}$ & 0 & 0 & 0 & 120 & 350 & 470 \\
\hline
\end{tabular}

Untuk item pelayanan ke-1 didapatkan jumlah skor kinerja sebesar 338 dan jumlah skor kepentingan sebesar 470.

Tabel 9 Skor Kinerja dan Kepentingan Pelayanan Ketersediaan Fasilitas Kesehatan

\begin{tabular}{|c|c|c|c|c|c|c|}
\hline \multicolumn{7}{|c|}{ TINGKAT KINERJA (Xi) } \\
\hline PENILAIAN & 1 & 2 & 3 & 4 & 5 & \\
\hline $\begin{array}{c}\text { JUMLAH } \\
\text { JAWABAN }\end{array}$ & 0 & 20 & 47 & 33 & 0 & \\
\hline JUMLAH SKOR & 0 & 40 & 141 & 132 & 0 & 313 \\
\hline \multicolumn{7}{|c|}{ TINGKAT KEPENTINGAN (Yi) } \\
\hline PENILAIAN & 1 & 2 & 3 & 4 & 5 & \\
\hline $\begin{array}{l}\text { JUMLAH } \\
\text { JAWABAN }\end{array}$ & 0 & 0 & 2 & 44 & 54 & \\
\hline JUMLAH SKOR & 0 & 0 & 6 & 176 & 270 & 452 \\
\hline
\end{tabular}

Untuk item pelayanan ke-2 didapatkan jumlah skor kinerja sebesar 313 dan jumlah skor kepentingan sebesar 452
Tabel 10 Skor Kinerja dan Kepentingan Pelayanan Kondisi Pintu Keluar Masuk Penumpang

\begin{tabular}{|c|c|c|c|c|c|c|}
\hline \multicolumn{7}{|c|}{ TINGKAT KINERJA (Xi) } \\
\hline PENILAIAN & 1 & 2 & 3 & 4 & 5 & \\
\hline $\begin{array}{l}\text { JUMLAH } \\
\text { JAWABAN }\end{array}$ & 0 & 5 & 59 & 33 & 3 & \\
\hline $\begin{array}{c}\text { JUMLAH } \\
\text { SKOR }\end{array}$ & 0 & 10 & 177 & 132 & 15 & 334 \\
\hline \multicolumn{7}{|c|}{ TINGKAT KEPENTINGAN (Yi) } \\
\hline PENILAIAN & 1 & 2 & 3 & 4 & 5 & \\
\hline $\begin{array}{c}\text { JUMLAH } \\
\text { JAWABAN }\end{array}$ & 0 & 0 & 1 & 36 & 63 & \\
\hline $\begin{array}{l}\text { JUMLAH } \\
\text { SKOR }\end{array}$ & 0 & 0 & 3 & 144 & 315 & 462 \\
\hline
\end{tabular}

Untuk item pelayanan ke-3 didapatkan jumlah skor kinerja sebesar 334 dan jumlah skor kepentingan sebesar 462.

Tabel 11 Skor Kinerja dan Kepentingan Pelayanan Kondisi Lampu Penerangan

\begin{tabular}{|c|c|c|c|c|c|c|}
\hline \multicolumn{7}{|c|}{ TINGKAT KINERJA (Xi) } \\
\hline PENILAIAN & 1 & 2 & 3 & 4 & 5 & \\
\hline $\begin{array}{l}\text { JUMLAH } \\
\text { JAWABAN }\end{array}$ & 0 & 4 & 54 & 39 & 3 & \\
\hline $\begin{array}{c}\text { JUMLAH } \\
\text { SKOR }\end{array}$ & 0 & 8 & 162 & 156 & 15 & 341 \\
\hline \multicolumn{7}{|c|}{ TINGKAT KEPENTINGAN (Yi) } \\
\hline PENILAIAN & 1 & 2 & 3 & 4 & 5 & \\
\hline $\begin{array}{l}\text { JUMLAH } \\
\text { JAWABAN }\end{array}$ & 0 & 0 & 0 & 35 & 65 & \\
\hline $\begin{array}{l}\text { JUMLAH } \\
\text { SKOR }\end{array}$ & 0 & 0 & 0 & 140 & 325 & 465 \\
\hline
\end{tabular}

Untuk item pelayanan ke-4 didapatkan jumlah skor kinerja sebesar 341 dan jumlah skor kepentingan sebesar 465

\section{KESIMPULAN}

Tingkat pelayanan yang diberikan PT. KAI khususnya DAOP 8 Surabaya dari segi tingkat kinerja dan kepentingan. Diketahui bahwa utuk tingkat kinerja pelayanan memiliki nilai rata-rata sebesar 3,14 yang dapat diartikan "Cukup Puas", sedangkan tingkat kepentingan memiliki nilai rata-rata sebesar 4,41 yang dapat diartikan "Penting". Kinerja pelayanan masih kurang dengan alasan kurangnya tenaga pelayanan. Fasilitas yang ada masih belum dapat memberikan kepuasan pada penumpang. Indeks kepuasan pelanggan yang dihitung menggunakan metode analisis 
CSI (Customer Satisfaction Index) menunjukkan nilai CSI sebesar 0,63 yang berarti penumpang KA Lokal Penataran "Cukup Puas" terhadap kinerja pelayanan yang diberikan KA Lokal Penataran.

\section{REFERENSI}

Hartono, As (2012), "LokomotIf dan kereta rel diesel"

Rika (2009), "Evaluasi Kualitas Pelayanan KA Ekonomi Kahuripan Relasi Kediri-Padalarang".

Ali (2011), "Evaluasi Kinerja Angkutan KRDI Sri Lelawangsa Lintas Medan-Binjai".

Sulistyowati, Retno Mulatsih, (2016), "Studi Kepuasan Penumpang Kereta Api Kamandaka Jurusan Semarang-Purwokerto", JDEB Vol.13, No.2

Farida, Fitriah Isky; Sarma, Ma'mun; Indrawan, Dikky (2011), Analisis Kepuasan Pelanggan Terhadap Kualitas Pelayanan Jasa Kereta Api Ekspres Pakuan Jabodetabek (Studi Kasus Kereta Api Ekspres Pakuan Bogor-Jakarta)", Repository IPB 